(1932) on congenital malformations and to Meves (1938). An explanation of this apparent rarity may lie in the difficulty of imaging the carpus. In our case there was no suggestion of a bar between the capitate and the lunate on standard radiographs. The patient denied any severe trauma or inflammation and the radiological abnormality is unlike any known post-traumatic pattern. It resembles more the common tarsal coalitions in which there is also a bony bar. The irregularities between the trapezoid and the capitate may represent another congenital deformity or be secondary adaptive changes resulting from the abnormal pattern of carpal motion.
No benefits in any form have been received or will be received from a commercial party related directly or indirectly to the subject of this article.

\section{REFERENCES}

Cope JR. Carpal coalition. Clin Radiol 1974; 25:261-6.

O'Rahilly R. A survey of carpal and tarsal anomalies. J Bone Joint Surg [Am] 1953; 35-A:626-42.

Poznanski AK, Holt JF. The carpals in congenital malformation syndromes. Am J Roentgenol Radium Ther Nucl Med 1971; 112:443-59.

Resnick D. Additional congenital or heritable anomalies and syndromes. In: Resnick D, Niwayama G, eds. Diagnosis of bone and joint disorders. Second ed, Vol. 5. Philadelphia, etc: W. B. Saunders Co, 1988:3541-96.

\title{
THE NATURAL HISTORY OF CONGENITAL PSEUDARTHROSIS OF THE CLAVICLE
}

\author{
AVSHALOM SHALOM, OVED KHERMOSH, SHLOMO WIENTROUB
}

There is still some controversy about the management of congenital pseudarthrosis of the clavicle, with divergent views on the need for excision and bone grafting with or without internal fixation (Alldred 1963; Jinkins 1969; Gibson and Carroll 1970; Owen 1970; Quinlan, Brady and Regan 1980; Schnall, King and Marrero 1988) or of simple excision of the pseudarthrosis for cosmetic purposes (Alldred 1963; Grogan et al 1991).

This benign condition rarely produces any functional disability; numerous operative complications have been reported (Alldred 1963; Owen 1970; Toledo and MacEwen 1979; Grogan et al 1991) and it seems worthwhile to present a very long follow-up of one case to help to document the natural history.

Case report. A 45-year-old male right-handed ENT surgeon had congenital pseudarthrosis of the right clavicle diagnosed in infancy. There were no other congenital anomalies and no other members of his family had the condition. On examination, there was subcutaneous swelling in the right midclavicular region (Fig. 1) with no tenderness or pain on movement. Shoulder movements were free and full and there was no muscle wasting or weakness. Clavicular lengths from joint to joint were equal. Radiographs confirmed the mobile pseudarthrosis

Shalom, MD Intern in Medicine

O. Khermosh, MD, Senior Lecturer in Orthopaedics

S. Wientroub, MD, Professor of Orthopaedics

Department of Pediatric Orthopaedics, Dana Children's Hospital, Tel-Aviv Medical Center, 6 Weizmann Street, Tel-Aviv 64239, Israel.

Correspondence to Professor S. Wientroub.

(C)1994 British Editorial Society of Bone and Joint Surgery

0301-620X/94/5R $12 \$ 2.00$

J Bone Joint Surg [Br] 1994; 76-B:846-7.

Received 10 September 1993; Accepted 14 October 1993
(Fig. 2). There were no arthritic changes in the pseudarthrosis or in the acromioclavicular joint.

The patient is active, performs delicate operations and enjoys sports activities. He wants no treatment and finds the disability acceptable except for the appearance.

Discussion. In childhood, congenital pseudarthrosis of the clavicle does not disturb function and if the prominence

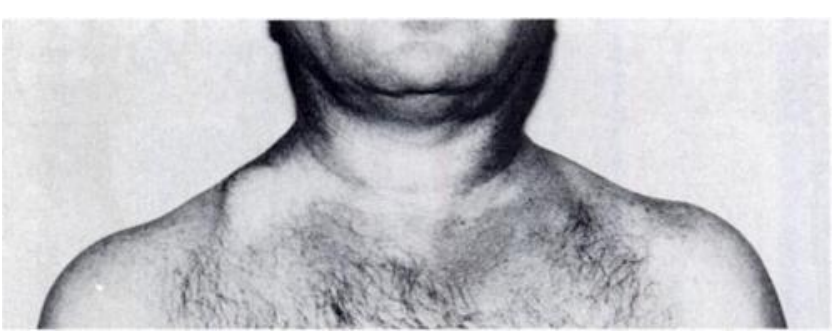

Fig. 1

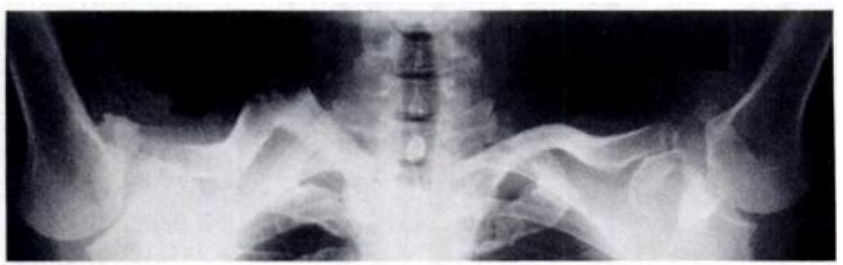

Fig. 2a

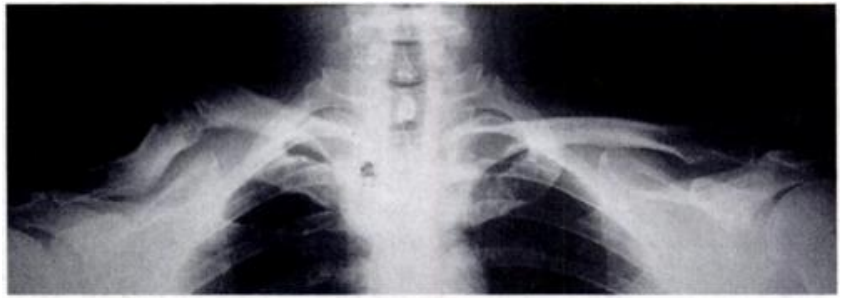

Fig. $2 b$ 
can be accepted, it is a benign condition. Our patient has shown no deterioration in function over a long period of time, or any secondary degenerative changes in the associated joints. Previous reports of conservative treatment have described only short follow-up (Wall 1970; Herman 1973; Ahmadi and Steel 1977) and so could not comment on late dysfunction or discomfort.

The reported complications of surgery include sepsis, scars on the shoulder and at the donor site of bone grafts, and delayed or nonunion requiring reoperation (Alldred 1963; Owen 1970). Brachial plexus injury has also been reported (Toledo and MacEwen 1979). Even simple resection of the pseudarthrosis to improve the cosmetic appearance has sequelae which include a postoperative difference in length and underdevelopment of the distal fragment with drooping of the shoulder (Tachdjian 1990; Grogan et al 1991). Conservative management appears to leave mild swelling with no functional disability, and should therefore be considered.

No benefits in any form have been received or will be received from a commercial party related directly or indirectly to the subject of this article.

\section{REFERENCES}

Ahmadi B, Steel HH. Congenital pseudarthrosis of the clavicle. Clin Orthop 1977; 126:129-34.

Alldred AJ. Congenital pseudarthrosis of the clavicle. J Bone Joint Surg [Br] 1963; 45-B:312-9.

Gibson DA, Carroll N. Congenital pseudarthrosis of the clavicle. J Bone Joint Surg [Br] 1970; 52-B:629-43.

Grogan DP, Love SM, Guidera KJ, Ogden JA. Operative treatment of congenital pseudarthrosis of the clavicle. J Pediatr Orthop 1991; 11:176-80.

Herman S. Congenital bilateral pseudarthrosis of the clavicles. Clin Orthop 1973; 91:162-3.

Jinkins WJ Jr. Congenital pseudarthrosis of the clavicle. Clin Orthop 1969; 62:183-6.

Owen R. Congenital pseudarthrosis of the clavicle.J Bone Joint Surg [Br] 1970; 52-B:644-52.

Quinlan WR, Brady PG, Regan BF. Congenital pseudarthrosis of the clavicle. Acta Orthop Scand 1980; 51:489-92.

Schnall SB, King JD, Marrero G. Congenital pseudarthrosis of the clavicle: a review of the literature and surgical results of six cases. $J$ Pediatr Orthop 1988; 8:316-21.

Tachdjian MO. Pediatric orthopaedics. 2nd ed. Philadelphia, etc: WB Saunders, 1990:168-74.

Toledo LC, MacEwen GD. Severe complication of surgical treatment of congenital pseudarthrosis of the clavicle. Clin Orthop 1979; 139:64-7.

Wall JJ. Congenital pseudarthrosis of the clavicle. J Bone Joint Surg [Am] 1970; 52-A:1003-9.

\section{DONOR SITE MORBIDITY AT THE ILIAC CREST: COMPARISON OF PERCUTANEOUS AND OPEN METHODS}

\section{NEIL KREIBICH, IAN R. SCOTT, JASON M. WELLS, MICHAEL SALEH}

The iliac crest is commonly used as a source for autogenous bone graft, but it may cause significant postoperative morbidity (Cockin 1971; Laurie et al 1984; Summers and Eisenstein 1989). In 1991, Saleh described a percutaneous method of harvesting bone from the iliac crest using a Meunier trephine. We have reviewed two series of patients to compare morbidity after this percutaneous approach and the standard open method.

Patients and methods. From 1985 to 1992 a total of 106 bone-grafting procedures have been performed by the senior author (MS). Of these, $86(81.1 \%)$ were reviewed. In 73 of these procedures (in 58 patients) non-structural

D. N. Kreibich, FRCS, Senior Orthopaedic Registrar

Sunderland District General Hospital, Kayll Road, Sunderland SR4 7TP, UK.

I. R. Scott, FRCS, Senior Orthopaedic Registrar

J. M. Wells, MB BS, House Officer

M. Saleh, MSc, FRCS, FRCS Ed, Senior Orthopaedic Lecturer and Honorary Consultant

The Limb Reconstruction Service, University Department of Orthopaedics, Northern General Hospital, Herries Road, Sheffield S5 7AU, UK.

Correspondence to Mr D. N. Kreibich at 42 Sanderson Road, Jesmond, Newcastle upon Tyne NE2 2DS, UK.

(C)1994 British Editorial Society of Bone and Joint Surgery

0301-620X/94/5R14 \$2.00

J Bone Joint Surg [Br] 1994; 76-B:847-8.

Received 22 November 1993; Accepted 1 December 1993 bone graft had been obtained from the anterior iliac crest by one of the two methods, 40 by the percutaneous technique and 33 by an open method with careful reconstruction of the iliac crest. Because of increasing use of the newer method the mean follow-up for the percutaneous group was 16 months compared with 33 months for the open method. The indications were the same and there were no other significant differences between the groups.

Results. The percutaneous technique was associated with significantly reduced postoperative pain, less pain on walking, less sensory disturbance and less local tenderness. Figure 1 shows that postoperative pain was described as moderate or severe by $25 \%$ of the percutaneous group, but by $61 \%$ of the open group $(p<0.02)$, and also gives the numbers of patients in each group. At latest review, none of the percutaneous group had pain on walking compared with seven of the patients in the open group $(p<0.05)$. Three of the percutaneous group had abnormal sensation around the donor site compared with 13 of the open group $(p<0.01)$. There was local scar tenderness in only one patient in the percutaneous group but in nine of the open group $(p<0.05)$. We found no significant differences between the groups for chronic rest pain, hip muscle power and the ability to lie on the side of the graft. 